\title{
Comparison of ultrasound guided interscalene brachial plexus block using $0.2 \%$ ropivacaine with dexmedetomidine and $0.2 \%$ ropivacaine with dexamethasone - A prospective observational study
}

\author{
Manasa Shekar ${ }^{1}$, Sushma Thimmaiah Kanakalakshmi', Shaji Mathew ${ }^{3 *}$, Shiyad Muhamed ${ }^{2}$, Arun \\ Kumar Handigodu Duggappa 4 , Basavaraj Herekar ${ }^{2}$ \\ Junior Resident ${ }^{1}$, Assistant Professor ${ }^{2}$, Professor ${ }^{3 *}$, Associate Professor ${ }^{4}$, Kasturba Medical College, \\ Manipal Academy of Higher Education, Manipal, India.
}

\begin{abstract}
Introduction
Adding adjuvants to local anaesthetics in brachial plexus block is known to enhance the quality and duration of analgesia. This study was undertaken to compare $1 \mu \mathrm{g} / \mathrm{kg}$ of dexmedetomidine, or $100 \mu \mathrm{g} / \mathrm{kg}$ of dexamethasone added as adjuvants to $0.2 \%$ ropivacaine in ultrasound guided interscalene brachial plexus block for arthroscopic shoulder surgeries.
\end{abstract}

\begin{abstract}
Subjects and methods
A prospective observational study in which 92 patients scheduled for arthroscopic shoulder surgery under ultrasound guided interscalene block with $15 \mathrm{ml}$ of $0.2 \%$ ropivacaine and dexmedetomidine (Dexmed) or dexamethasone (Dexa) as adjuvants. Onset, duration of sensory and motor blockade, sedation score, time for rescue analgesia (duration of analgesia) were recorded and analysed.
\end{abstract}

\section{Results}

Demographic data and surgical characteristics were similar in both the groups. Sensorimotor blockade onset was earlier in group Dexmed $(8.67 \pm 3.06 \mathrm{~min})$ as compared to group Dexa $(14.61 \pm 6.71 \mathrm{~min})[\mathrm{P}<0.001]$. Blockade duration was longer in group Dexmed than group Dexa. Time of request for rescue analgesia was delayed in group Dexmed (930.0 \pm 83.45 min) when compared to group Dexa $(620.0 \pm 125.54 \mathrm{~min})$. Mild sedation was observed in group Dexmed.

\begin{abstract}
Conclusion
Dexmedetomidine as an adjuvant to $0.2 \%$ ropivacaine in ultrasound guided interscalene blockade is more efficacious than dexamethasone in hastening the onset, prolonging sensory blockade and delaying the time of request for rescue analgesia. Dexmedetomidine produces mild sedation compared to dexamethasone as an adjuvant.
\end{abstract}

Keywords: Interscalene brachial plexus block; adjuvants; dexmedetomidine; dexamethasone

\section{Introduction}

Arthroscopic shoulder surgeries can be done under general anaesthesia, regional anaesthesia or a combination of both. In patients undergoing shoulder arthroscopy, pain can persist for more

*Correspondence: Shaji Mathew

E mail: shajimanipal@yahoo.co.in

https://orcid.org/0000-0001-8992-8339

Received: $17 / 04 / 2020$

Accepted: 15/06/2020

DOI: http:/doi.org/10.4038/slja.v28i2.8574

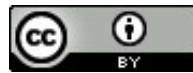

than 48 hours in the postoperative period despite multimodal analgesia, thus making pain control challenging for anaesthesiologists.

Effective postoperative pain management is important for initiating rehabilitation, thus decreasing hospital stay and improving patient satisfaction. Various analgesic regimens like intravenous, oral and transdermal patches have been tried to control postoperative pain but with certain limitations.

Interscalene brachial plexus block is one of the most widely practiced regional anaesthetic technique for shoulder surgeries and it provides better analgesia, greater satisfaction and fewer side effects. When combined with general 
anaesthesia, it reduces intraoperative anaesthetic and analgesic requirements and provides postoperative analgesia.

Adjuvants to local anaesthetics improve the quality of analgesia, prolong duration of blockade and reduce the dose of local anaesthetics. ${ }^{1-4}$ In this study we observed and compared the efficacy of two adjuvants - dexmedetomidine and dexamethasone with $0.2 \%$ ropivacaine. Aim of the study was to compare the block characteristics with dexmedetomidine and dexamethasone as adjuvants to $0.2 \%$ ropivacaine in ultrasound guided (USG) interscalene block for arthroscopic shoulder surgeries. Comparison of onset and duration of sensory blockade was our primary objective. Secondary objectives were to compare the onset, duration of motor blockade, time of request for rescue analgesia and sedation score.

\section{Subjects and methods}

Institutional ethics committee approval was sought before commencing this prospective observational study. Clinical Trials Registry of India (CTRI) registration was done. Patients of American Society of Anaesthesiologists physical status (ASA PS) I or II, aged 18 - 60 years of either gender scheduled for elective arthroscopic shoulder surgeries under interscalene block using $15 \mathrm{ml}$ of $0.2 \%$ ropivacaine with $1 \mu \mathrm{g} / \mathrm{kg}$ of dexmedetomidine or $100 \mu \mathrm{g} / \mathrm{kg}$ of dexamethasone as adjuvants along with general anaesthesia were included in the study. Patients who refused to participate, those with neurological deficits, known allergy to local anaesthetics and history of seizures were excluded. Informed consent was obtained from all participants. Consultant anaesthesiologists administered the USG guided interscalene blocks with $0.2 \%$ ropivacaine and adjuvant of their choice (dexmedetomidine or dexamethasone). Patients who received dexmedetomidine as adjuvant were observed under group Dexmed and who received dexamethasone as adjuvant were observed under group Dexa. Observed parameters include onset of sensory and motor block, duration of sensory and motor block, sedation score and time for rescue analgesia. The time interval between administration of local anaesthetic solution to loss of prick sensation in C5, 6, 7 dermatomes was taken as onset time; it was assessed every 3 min till complete loss of sensation for $30 \mathrm{~min}$. Three point scale was used to assess the sensory blockade (Grade 0: Sharp prick felt, Grade 1: Analgesia, dull sensation felt, Grade 2: Anaesthesia, no sensation felt). Onset of motor blockade was defined as the duration from injection of local anaesthetic solution to loss of movements in the arm, assessed every $3 \mathrm{~min}$ for 30 min using modified Bromage scale (Grade 0: Normal motor function, Grade 1: Ability to move only fingers, Grade 2: Complete motor block with inability to move below the wrist and finger). Time interval between complete loss of sensation on toothpick prick to reappearance of sensations was considered as duration of sensory blockade. Interval between complete motor blockade to reappearance of movements was regarded as duration of motor blockade. Sensory blockade of less than grade 2, for $30 \mathrm{~min}$ following administration of study drug was considered as unsuccessful blockade and those patients were excluded from analysis. Interval between administration of block to request for any pain relieving medications by the patient was considered as time for rescue analgesia. Fivepoint sedation score described by Culebras et al. was used for assessing sedation. ${ }^{5}$ Once the parameters were noted, general anaesthesia was administered as per the standard protocol. Any additional dose of analgesic administered were documented. Post-operative follow-up was done every $30 \mathrm{~min}$ to measure the outcomes mentioned earlier.

\section{Sample size}

Calculated based on the duration of sensory blockade (pilot study). To consider 30\% difference in duration of sensory blockade between the groups to be significant, with an alpha error of 0.05 and power of $80 \%$, sample size calculated was 92 with 46 patients in each group.

Formula used

$\mathrm{n}=2\left[\mathrm{Z}_{1-\alpha / 2}+\mathrm{Z}_{1-\beta}\right]^{2} \sigma^{2} \div \mathrm{d}^{2}$

where, $Z_{1-\alpha / 2}=1.96$ for alpha at $5 \%$ level of significance

$\mathrm{Z}_{1-\beta}=0.84$ for $80 \%$ power

$\mathrm{d} / \sigma=$ effect size $(0.5=$ anticipated value $)$

\section{Results}

All the 92 patients enrolled have completed the study with nil dropouts and none had failed block. The data were analysed using SPSS version 16 software. Continuous data were represented as 
mean $\pm \mathrm{SD}$ and categorical data as number of patients. Independent $\mathrm{t}$-test and Chi-square tests were used for data analysis. P- value of $<0.05$ was considered as significant. Sixty-nine male and twenty-three female patients participated in the study. Sixty-five patients belonged to ASA PS I and 27 patients belonged to ASA PS II. Age, weight and the duration of surgery were comparable between groups. Onset of sensorimotor blockade was significantly longer in group Dexa compared to group Dexmed (Table 1). The duration of sensorimotor blockade and time for request of rescue analgesia was significantly prolonged in group Dexmed compared to group Dexa (Table 2). Statistically significant sedation was observed in group Dexmed than group Dexa (Table 3). Intraoperatively none of the patients required any additional dose of analgesics.

Table 1:

Onset of blockade (Mean \pm SD)

\begin{tabular}{|l|l|l|l|}
\hline & $\begin{array}{l}\text { Group Dexmed } \\
(n=46)\end{array}$ & $\begin{array}{l}\text { Group Dexa } \\
(n=46)\end{array}$ & P value \\
\hline $\begin{array}{l}\text { Sensory onset } \\
\text { (min) }\end{array}$ & $8.67 \pm 3.06$ & $14.61 \pm 6.71$ & $0.001^{*}$ \\
\hline Motor onset(min) & $13.96 \pm 5.06$ & $19.47 \pm 6.97$ & $0.001^{*}$ \\
\hline
\end{tabular}

* Independent t-test

Table 2:

Duration of blockade and time to rescue analgesia $($ Mean \pm SD)

\begin{tabular}{|l|l|l|l|}
\hline & $\begin{array}{l}\text { Group Dexmed } \\
(\mathrm{n}=46)\end{array}$ & $\begin{array}{l}\text { Group Dexa } \\
(\mathrm{n}=46)\end{array}$ & $\begin{array}{l}\mathrm{P} \\
\text { Value }\end{array}$ \\
\hline $\begin{array}{l}\text { Sensory blockade } \\
(\mathrm{min})\end{array}$ & $884.0 \pm 85.46$ & $564.13 \pm 83.22$ & $0.001^{*}$ \\
\hline $\begin{array}{l}\text { Motor blockade } \\
\text { (min) }\end{array}$ & $\begin{array}{l}823.70 \pm \\
128.25\end{array}$ & $522.0 \pm 76.89$ & $0.001^{*}$ \\
\hline $\begin{array}{l}\text { Time to rescue } \\
\text { analgesia (min) }\end{array}$ & $930.0 \pm 83.45$ & $620.0 \pm 125.54$ & $0.001^{*}$ \\
\hline
\end{tabular}

*Independent t-test

Table 3:

Sedation score

\begin{tabular}{|l|l|l|}
\hline \multirow{2}{*}{ Group } & Sedation score \\
\cline { 2 - 3 } & $\begin{array}{l}1 \\
\text { (Awake and alert) }\end{array}$ & $\begin{array}{l}2 \\
\text { (Sedated, responding } \\
\text { to verbal stimulus) }\end{array}$ \\
\hline $\begin{array}{l}\text { Dexmed } \\
(\mathrm{n}=46)\end{array}$ & 29 & 17 \\
\hline Dexa $(\mathrm{n}=46)$ & 45 & 1 \\
\hline P value- 0.001 & \multicolumn{2}{c|}{ Chi-square test }
\end{tabular}

\section{Discussion}

The benefits of regional anaesthesia, wherever feasible, is very well recognized. Ropivacaine is an amide local anaesthetic, less potent than bupivacaine. Being 10 times less lipid soluble compared to bupivacaine renders it less cardiotoxic. ${ }^{6}$ Regional anaesthesia with local anaesthetics alone has limitations such as systemic toxicity, regression of block amidst surgery and requirement of additional sedation leading to side effects. Hence the concept of adding adjuvants to local anaesthetics came into practice. Additives provide quicker onset, prolonged dense blockade with reduction in the requirement of systemic analgesics and improves patient satisfaction. Several studies are available till date to find out efficacy of various adjuvants. ${ }^{2-}$ ${ }^{4}$ Dexmedetomidine is an alpha-2 adrenoreceptor agonist used as an adjuvant in neuraxial and peripheral nerve blocks. Mechanism of action is hypothesised to be multifactorial with both peripheral and central actions. Dexmedetomidine was approved by FDA in 1999 as a short acting sedative in intensive care setting. ${ }^{4}$ It has gained popularity in recent years due to its sympatholytic, sedative, analgesic as well as amnestic properties. Various studies have proven that dexmedetomidine, as an adjuvant to local anaesthetics in peripheral nerve blocks prolongs the duration of sensorimotor blockade. ${ }^{7-9}$ Being a glucocorticoid, dexamethasone is known to reduce tissue damage and inflammation by reducing the production and maintenance of inflammatory mediators and hence pain perception. It activates glucocorticoid receptor and inhibit phospholipase A2. Extended analgesic effect of dexamethasone is attributed to increased activity of inhibitory potassium channels in nociceptive C-fibres. ${ }^{10} \mathrm{~A}$ study by Bani et al. observed that when dexamethasone was used as an additive in spinal anaesthetic, it extends the duration of block without any side effects. ${ }^{11}$ Metaanalysis conducted by Jebraj et al highlights the advantages of use of dexamethasone at a dose of $4-8 \mathrm{mg}$ in epidural analgesia along with usual local anaesthetic solutions. ${ }^{12}$ However, it also emphasised the necessity of further studies to know its safety with respect to neurological complications. The onset of both sensory and motor block was quicker in group Dexmed compared to group Dexa. The onset of sensory block in group Dexmed and group Dexa was $8.67 \pm 3.06$ and $14.61 \pm 6.71 \mathrm{~min}$ 
respectively. This was found to be statistically significant (Table 1). Similarly, the onset of motor block in group Dexmed and group Dexa was $13.96 \pm 5.06 \mathrm{~min}$ and $19.47 \pm 6.97 \mathrm{~min}$ respectively. Significantly longer sensory blockade was observed in group Dexmed ( $884 \pm$ $85.46 \mathrm{~min})$ than group Dexa (564.13 \pm 83.22 min). Similarly, motor blockade was also prolonged with addition of dexmedetomidine over dexamethasone with mean duration of $823.70 \pm 128.25 \mathrm{~min}$ and $522 \pm 76.89 \mathrm{~min}$ respectively, which was found to be significant (Table 2). Time to request of first rescue analgesia was also prolonged in group Dexmed $(930 \pm 83.45 \mathrm{~min})$ than in group Dexa (620 \pm $125.54 \mathrm{~min}$ ), which is clinically and statistically significant (Table 2). Our results were similar to the results obtained by Verma NK et al and Kaur $M$ et al. ${ }^{13,14}$ However Lee MJ et al. observed that the sensory blockade was prolonged with dexmedetomidine or dexamethasone as adjuvants compared to plain ropivacaine, but there was no significant intergroup difference between dexmedetomidine and dexamethasone. Significant differences in onset time was not noticed among three groups, which is attributable to the higher dose of local anaesthetic. ${ }^{15}$ A study conducted by Jadon A et al showed that dexamethasone as an adjuvant to ropivacaine had no effect on the onset of sensorimotor block in interscalene block. However, there was significant prolongation of block duration. ${ }^{16}$ In our study, higher incidence of sedation, although mild was observed in group Dexmed (17 patients) compared to group Dexa (one patient). Although statistically highly significant, the observed sedation scores were clinically insignificant (Table 3). This was similar to the results obtained by Verma $\mathrm{N}$ etal. ${ }^{13}$ Sridhar et al. did not observe any significant sedation among the groups with dexmedetomidine or dexamethasone as adjuvants with ropivacaine in caudal block. ${ }^{17}$ This may be hypothesised due to higher volume of the local anaesthetics in caudal block compared to the adjuvant making its concentration lesser than what we used in our study. Bradycardia and hypotension are one of the most common adverse effects of alpha -2 agonists. ${ }^{18} \mathrm{We}$ did not come across such events in our study, which is likely due to smaller doses used. Use of adjuvants in nerve blocks is a well-established practice globally. Our observations affirm that dexmedetomidine can be considered a better adjuvant than dexamethasone.

\section{Conclusion}

Dexmedetomidine as an adjuvant to $0.2 \%$ ropivacaine in ultrasound guided interscalene blockade is more efficacious than dexamethasone in hastening the onset, prolonging sensorimotor blockade and delaying the time for request of rescue analgesia.

Dexmedetomidine produces more sedation in comparison to dexamethasone when used as an adjuvant in interscalene blocks.

\section{References}

1. Swain A, Nag DS, Sahu S, Samaddar DP. Adjuvants to local anesthetics: Current understanding and future trends. World J Clinical Cases 2017; 5: 307-23.

https://doi.org/10.12998/wjcc.v5.i8.307

PMid:28868303 PMCid:PMC5561500

2. Bazin JE, Massoni C, Bruelle $\mathrm{P}$ et al. The addition of opioids to local anaesthetics in brachial plexus block: the comparative effects of morphine, buprenorphine and sufentanil. Anaesthesia 1997; 52: $858-62$.

https://doi.org/10.1111/j.1365-2044.1997.174az0311.x

PMid:9349066

3. Choi S, Rodseth R, McCartney CJ. Effects of dexamethasone as a local anaesthetic adjuvant for brachial plexus block: a systematic review and meta-analysis of randomized trials. $\mathrm{Br} \mathrm{J}$ Anaesth 2014; 112: 427-39.

https://doi.org/10.1093/bja/aet417 PMid:24413428

4. Swami SS, Keniya VM, Ladi SD, Rao R. Comparison of dexmedetomidine and clonidine ( $\alpha 2$ agonist drugs) as an adjuvant to local anaesthesia in supraclavicular brachial plexus block: A randomised double-blind prospective study. Indian J Anaesth 2012; 56: 243-9. https://doi.org/10.4103/0019-5049.98767 PMid:22923822 PMCid:PMC3425283

5. Culebras X, Van Gessel E, Hoffmeyer P, Gamulin Z. Clonidine combined with a long acting local anesthetic does not prolong postoperative analgesia after brachial plexus block but does induce hemodynamic changes. AnesthAnalg 2001; 92: 199-204.

https://doi.org/10.1097/00000539-200101000$\underline{00038}$

PMid:11133627

6. McClure JH. Ropivacaine. Br J Anaesth. 1996; 76: 300-7.

https://doi.org/10.1093/bja/76.2.300

PMid:8777115 
7. Esmaoglu A, Yegenoglu F, Akin A, Turk CY. Dexmedetomidine added to levobupivacaine prolongs axillary brachial plexus block. AnesthAnalg 2010; 111: 1548-51. https://doi.org/10.1213/ANE.0b013e3181fa3095 PMid:20889939

8. Kaygusuz K, Kol IO, Duger C et al. Effects of adding dexmedetomidine to levobupivacaine in axillary brachial plexus block. Current therapeutic research 2012; 73: 103-11. https://doi.org/10.1016/j.curtheres.2012.03.001 PMid:24648597 PMCid:PMC3954022

9. Gandhi R, Shah A, Patel I. Use of dexmedetomidine along with bupivacaine for brachial plexus block. Natl J Med Res 2012; 2: 67-9.

10. Gao Z, Xiao Y, Wang Q, Li Y. Comparison of dexmedetomidine and dexamethasone as adjuvant for ropivacaine in ultrasound-guided erector spinae plane block for video-assisted thoracoscopic lobectomy surgery: a randomized, double-blind, placebo-controlled trial. Ann Transl Med 2019;7:668.

https://doi.org/10.21037/atm.2019.10.74

PMid:31930069 PMCid:PMC6944602

11. Bani-Hashem N, Hassan-Nasab B, Pour EA et al. Addition of intrathecal dexamethasone to bupivacaine for spinal anesthesia in orthopedic surgery. Saudi J Anaesth 2011; 5: 382-86. https://doi.org/10.4103/1658-354X.87267 PMid:22144925 PMCid:PMC3227307

12. Jebaraj B, Khanna P, Baidya DK, Maitra S. Efficacy of epidural local anesthetic and dexamethasone in providing postoperative analgesia: A meta-analysis. Saudi J Anaesth 2016; 10: 322-27.

https://doi.org/10.4103/1658-354X.179096 PMid:27375389 PMCid:PMC4916818

13. Verma NK, Ranjan A. A clinical comparison of dexmedetomidine and dexamethasone as adjuvant to ropivacaine in supraclavicular brachial plexus blocks for upper arm surgeries. Int J Adv Res Biol Sci 2016; 3: 56-61.

14. Kaur M, Lakhani A, Hashia AM. Comparative study between dexamethasone and dexmedetomidine in supraclavicular block. Int $\mathrm{J}$ Adv Med 2018; 5: 57-61. https://doi.org/10.18203/23493933.ijam20175878

15. Lee MJ, Koo DJ, Choi YS et al. Dexamethasone or dexmedetomidine as local anesthetic adjuvants for ultrasound-guided axillary brachial plexus blocks with nerve stimulation. The Korean J Pain 2016; 29:29-33. https://doi.org/10.3344/kjp.2016.29.1.29 PMid:26839668 PMCid:PMC4731548

16. Jadon A, Dixit S, Kedia $\mathrm{S}$ et al. Interscalene brachial plexus block for shoulder arthroscopic surgery: Prospective randomised controlled study of effects of $0.5 \%$ ropivacaine and $0.5 \%$ ropivacaine with dexamethasone. Indian $\mathrm{J}$ Anaesth 2015; 59: 171-6. https://doi.org/10.4103/0019-5049.153039 PMid:25838589 PMCid:PMC4378078

17. Sridhar RB, Kalappa S, Nagappa S. Nonopioid (Dexmedetomidine, Dexamethasone, Magnesium) adjuvant to ropivacaine caudal anesthesia in pediatric patients undergoing infraumbilical surgeries: A comparative study. Anesth Essays Res 2017; 11: 636-41. https://doi.org/10.4103/0259-1162.206853 PMid:28928562 PMCid:PMC5594781

18. Albrecht E, Vorobeichik L, Jacot-Guillarmod A et al. Dexamethasone is superior to dexmedetomidine as a perineural adjunct for supraclavicular brachial plexus block. AnesthAnalg 2019; 128: 543-54. https://doi.org/10.1213/ANE.0000000000003860 PMid:30303864 